Paweł Gąska

Uniwersytet Mikołaja Kopernika, Toruń

e-mail: skrzynka.pawla.gaski@gmail.com

\title{
Przejawy społecznych lęków przed technologią w grach cyfrowych
}

DOI: http://dx.doi.org/10.12775/RF.2018.016

\section{Wstęp}

Niemalże nieludzkie cyborgi i niemalże ludzkie androidy, zmutowane, groteskowe ludzkie hybrydy, zdezorientowane w swojej egzystencji klony, zbuntowane Sztuczne Inteligencje, połączone w jeden umysł-rój zbiorowości, broń masowej zagłady i broń precyzyjnej (ale jednostkowej) zagłady; zabójcze wirusy biologiczne i niebezpieczne wirusy wirtualne, krążące po cyberprzestrzeni - sztafaż motywów groźnej, przerażającej i zarazem fascynującej technologii, jakim posługują się gry cyfrowe ${ }^{1}$ o tematyce science fiction, jest naprawdę bogaty. I chociaż w innych mediach (książkach, filmach, komiksach) również znajdziemy te motywy, to gry, dzięki leżącej u ich podstaw interaktywności, oferują specyficzne sposoby wyrażania tych wątków. Począwszy od oddania niebezpiecznych technologii w ręce awatara gracza, a kończąc na próbie przekonania odbiorcy, że gra wyrywa mu się spod kontroli - środki, którymi gry cyfrowe mogą się posługiwać są bardzo zróżnicowane.

Opowiadanie o lękach przed konsekwencjami technologicznych innowacji za pomocą gier jest podwójnie ciekawe, ze względu na to, jak uwikłanie $\mathrm{w}$ relacje $\mathrm{z}$ nowoczesnymi urządzeniami wpisane jest w samą naturę

1 Do tej kategorii wliczają się zarówno gry komputerowe, konsolowe, jak i mobilne. Synonimicznie używam również pojęcia "gry wideo" lub po prostu "gry". 
medium. Gry są jednym z motorów napędzających rozwój sektora elektroniki - to one potrzebują potężniejszych kart graficznych i bardziej wydajnych procesorów; to one kreują marzenie o wirtualnej rzeczywistości leżące u podstaw rozwoju technologii VR. Występowanie krytyki technonauki w grach wydaje się paradoksalnym zjawiskiem, jest jednak czymś, co często pojawia się zarówno w wysokobudżetowych komercyjnych produkcjach, jak i w grach niezależnych. I chociaż trzeba za Nickiem Dyer-Withefordem i Greigiem de Peuterem podkreślić ambiwalencję takich „dysonansów w projektowaniu" ${ }^{2}$ - elementy sceptyczne wobec rozwoju technologii często zmieszane są z mechanikami gry, pozwalającymi graczowi korzystać z rzeczonych technologii ${ }^{3}$ - to warto też przyjrzeć się, w jaki sposób owe lęki są przedstawiane. Taki jest cel tego artykułu szeroka analiza przejawów techno-lęków w wybranej, reprezentatywnej próbie gier wideo. W tym celu trzeba odpowiedzieć na dwa pytania: jakie lęki są szczególnie często podejmowane w grach i jakimi metodami są one prezentowane.

\section{Czego się boimy?}

Odpowiedź na pierwsze pytanie trzeba poprzedzić pewnym umocowaniem metodologicznym rozważań. Nie chodzi tutaj bowiem o strach w rozumieniu psychologicznym, jako reakcję organizmu na bodziec uznawany za groźny, czy jako mniej lub bardziej irracjonalną fobię przed konkretnym typem zjawiska. Lęki przed technologią ujawniające się w artefaktach kulturowych czy zachowaniach określonych wspólnot, należy odczytywać właśnie społecznie - jako pewien niepokój przed negatywnymi konsekwencjami innowacji technologicznych, pewien wariant lęku przed zmianami. Ten typ lęków jest przejawem funkcjonowania tzw. społeczeństwa ryzyka ${ }^{4}$. Termin ten ukuty przez Ulricha Becka ${ }^{5}$, ale podejmowany w pewnych wariantach również przez Anthony'ego Giddensa $^{6}$ ma opisywać współczesne, ponowoczesne społeczeństwa, które z jednej strony wytwarzają coraz to nowe zagrożenia, a z drugiej są coraz bardziej świadome ich występowania (nawet jeśli często

2 N. Dyer-Witheford, G. de Peuter, Games of Empire. Global Capitalism and Video Games, University of Minnesota Press, Minneapolis-London 2009.

3 Kilka przykładów takich gier to: System Shock 2, Bioshock, Deus Ex: Bunt Ludzkości, Remember Me, Prototype i inne.

4 O czym pisałem już wcześniej w kontekście postapokalips. Patrz: P. Gąska, Historia rozwoju konwencji postapokaliptycznej jako odbicie lęków kultury zachodniej, „Annales Universitatis Mariae Curie-Sklodowska, sectio FF-Philologia” 2016, nr 34, s. 13-32.

5 U. Beck, Społeczeństwo ryzyka. W drodze do innej nowoczesności, Wydawnictwo Naukowe Scholar, Warszawa 2002.

6 U. Beck, A. Giddens, S. Lash, Modernizacja refleksyjna. Polityka, tradycja i estetyka w porządku społecznym nowoczesności, Wydawnictwo Naukowe PWN, Warszawa 2009. 
nie chcą przyjąć ich istnienia - jak w przypadku globalnego ocieplenia). Taka kombinacja, określana jako „modernizacja refleksyjna"7, jest źródłem różnego rodzaju niepokojów. W przypadku wielu typów ryzyka możliwość poradzenia sobie przez jednostkę z danym zagrożeniem jest zerowa lub bardzo niska. Jednym ze sposobów radzenia sobie z wyrastającą $\mathrm{z}$ tego frustracją i lękiem jest przedstawienie danego zagrożenia w różnych dziełach medialnych, co zarazem oswaja wcześniej niesprecyzowane zagrożenie, jak również daje okazję na poradzenie sobie z nim (czy raczej z jego uproszczoną wersją) wewnątrz diegetycznego świata opowieści. Pytanie o to, jakie lęki pojawiają się w grach, jest więc zarazem pytaniem, jakie zjawiska wywołują poczucie zagrożenia, wymagające medialnego uspokojenia.

Koncepcję ryzyka trzeba rozszerzyć o jeszcze jeden element - Teorię Aktora-Sieci Bruno Latoura. Wartość takiego połączenia znakomicie pokazuje w swojej książce Ewa Bińczyk ${ }^{8}$. Wskazuje ona, że ryzyko nie jest $\mathrm{w}$ żadnym razie stanem naturalnym, ale że powstaje na skrzyżowaniu ekspertów, przemysłu, mediów, zwykłych obywateli i nowoczesnych technologii - aktorów ludzkich i pozaludzkich. „Ryzyko [...], będąc rodzajem wirtualnej rzeczywistości [...], wymaga mediacji: naukowej, politycznej, publicznej oraz ekonomicznej. Ogromną rolę odgrywają w tym kontekście środki masowego przekazu" ${ }^{\prime 9}$. Jest ono zarazem oswajane jak i nagłaśniane poprzez różnego rodzaju dyskursy, które o nim opowiadają. Również dzieła fikcyjne wpisują się w ten proces, ukazując, które tematy są $w$ danym momencie $w$ centrum uwagi i zarazem zwiększając szum informacyjny wokół nich. ANTowska metodologia nie jest co prawda (bez dodatkowych uszczegółowień) najlepiej przystosowana do analiz fikcyjnych opowieści, jednak perspektywa badawcza uwzględniająca ANT pozwala nam dostrzec interesujące zależności. Zagadnienie ryzyka okazuje się kwestią stabilności i destabilizacji konkretnych ludzko-pozaludzkich sieci, więc studium technologicznych lęków w grach wideo $\mathrm{w}$ istocie dotyczy niepokojów wywołanych zmianami w sieciach relacji, w których ludzie uczestniczą. Wśród nich możemy wyróżnić cztery główne relacje, wokół których zbudowane są różne warianty lęków przed nową technologią: (1) relacja człowieka z samym soba, (2) relacja człowieka z narzędziem, (3) relacja człowieka z instytucjami społecznymi i wreszcie (4) relacja człowieka ze środowiskiem. Przyjrzyjmy się im bliżej.

7 Ibidem.

8 E. Bińczyk, Technonauka w społeczeństwie ryzyka. Filozofia wobec niepożądanych następstw praktycznego sukcesu nauki, Wydawnictwo Naukowe UMK, Toruń 2012.

9 Ibidem. 


\subsection{Relacja człowieka z samym sobą - cielesność, umysł i wolna wola}

Wśród różnych konsekwencji rozwoju technologicznego, z jakimi można się zetknąć lub które można sobie wyobrazić, jedną z najbardziej niepokojących jest wpływ technologii na funkcjonowanie samego człowieka. $\mathrm{Z}$ jednej strony pojawiają się transhumanistyczne obietnice ulepszenia ludzkości, czy to poprzez modyfikacje ciała czy przeniesienie umysłu do innego nośnika ${ }^{10}$. Z drugiej wszechobecne związki chemiczne negatywnie wpływają na ludzkie organizmy, powodując bolesne schorzenia czy upośledzając na całe życie. Rozwój medycyny przez ostatnie kilka stuleci sprawił, że ludzie są dużo bardziej świadomi potrzeby dbania o własne ciało, z kolei rozwój internetu uczynił każdego użytkownika wyszukiwarki Google domorosłym lekarzem. Nic zatem dziwnego, że jednym z ważniejszych motywów science-fiction (nie tylko tej growej) jest kwestia przekształceń w cielesności - na lepsze lub na gorsze - jaka może nas czekać w mniej lub bardziej odległej przyszłości. Lista możliwych zmian jest długa, jednak tematy najczęściej poruszane $\mathrm{w}$ grach wideo krążą wokół kilku powtarzających się wątków.

Pierwszym i chyba najczęstszym jest zagrożenie monstrualizacją przekształceniem ludzkiego ciała $\mathrm{w}$ jakiś przerażający, groteskowy twór, który nie ma już wiele wspólnego z tym, co klasycznie pojmuje się jako ludzkie. Motyw potwora będącego ludzko-nieludzką hybrydą towarzyszy ludzkości już od jej zarania. Jest w niego wpisany strach przed innością oraz przed deformacją czy kalectwem. O ile jednak kiedyś skupiał się on na ingerencjach sił magicznych (jak w baśniach czy legendach) lub służył piętnowaniu odmienności fizycznych, rasowych czy seksualnych, o tyle w XIX wieku przeszedł on do skrzynki z narzędziami twórców opowieści grozy, którzy często i chętnie wykorzystywali go do krytyki niekontrolowanego rozwoju nauki ${ }^{11}$. Deformacje fizyczne są tutaj często utożsamiane ze złem moralnym. Motyw ten swoją wyrazistość zawdzięcza łatwości, z jaką można ocenić, że dana istota odbiega od standardowego wizerunku człowieka. Nieproporcjonalne kończyny, niepokojący rozrost tkanek, nabranie cech zwierzęcych (kły, szpony, warczenie etc.) czy wszelkiego rodzaju rany i obrażenia na ciele takiej istoty (szczególnie w przypadku zombie) jednoznacznie wskazują że

10 Więcej na temat transhumanistycznych wątków w grach cyfrowych piszę we wcześniejszym artykule, patrz: P. Gąska, Degeneracja, cyborgizacja, ewolucja - przedstawienia transhumanistycznych utopii i dystopii w grach komputerowych, „Śląskie Studia Polonistyczne" 2017, nr 1, s. 153-172.

11 Patrz choćby Frankestein Mary Shelley. 
mamy do czynienia z czymś nieludzkim, "materią nie na miejscu”12. Strach miesza się często z obrzydzeniem, kiedy spotykamy wyjątkowo groteskowe stwory zamieszkujące światy Bioshocka, Prototypa, Falloutów czy Dying Lighta. Twórcy doskonale zdają sobie z tego sprawę i dlatego obsadzają je najczęściej w roli przeciwników do pokonania, rzadziej zaś jako postacie niezależne, z którymi można wejść w nie-agresywną interakcję. Doskonale pasują one do roli wrogów - jeszcze na tyle ludzkie, żeby gracz czuł, że walczy z inteligentnymi przeciwnikami, ale już na tyle nieludzkie, żeby gracz nie czuł się źle, zabijając setki z nich podczas swojej podróży przez świat danej gry. Są też bardzo czytelnym, jednoznacznym przekazem na temat tego, do czego mogą prowadzić niekontrolowane eksperymenty z zakresu biotechnologii. Warto $\mathrm{w}$ tym miejscu nadmienić, że chociaż przemiana biologiczna jest najbardziej popularną drogą monstrualizacji, to pojawiają się też potwory powstałe na drodze ulepszeń technologicznych - cyborgizacji. Przerażające "cyborgiczne położne (ang. cyborg midwife)" z System Shocka 2 - kobiety, których cała dolna połowa ciała została wymieniona na ciało robota przez szaloną sztuczną inteligencję - czy żyjący w ciągłym bólu olbrzymi „majstrowie" (ang. handyman) z Bioshock: Infinite, połączeni z "Automatycznymi Ciałami (ang. Autobody)", którzy utracili zdolność zasypiania, to tylko dwa przykłady zdegenerowanych cyborgów, zaludniających wirtualne światy.

Najczęściej jednak motyw ulepszania ludzkiego ciała za pomocą zaawansowanej technologii opowiadany jest w inny sposób. Zagrożenie nie dotyczy w tak dużym stopniu zepsucia ciała, co utraty kontroli nad nim i nad swoimi działaniami. Innymi słowy, na pierwszy plan wysuwana jest kwestia wolnej woli i bycia jej pozbawionym. Nie będę tutaj próbował rozstrzygnąć wieloletniej debaty podejmowanej przez różnych filozofów wokół tego, czy wolna wola istnieje, czy też jest jedynie iluzją wytwarzaną na potrzeby świadomości. W grach, które podejmują ten temat, musi być przyjęte założenie, że wolna wola istnieje, oraz że za pomocą technologicznych ingerencji w ludzkie ciało może być ona odebrana. Tutaj również pojawiają się zdehumanizowani wrogowie (choćby przypominające marionetki cyborgi Iluminatów z Deus Ex: Invisible War), jednak specyfika medium gier oferuje jeszcze jedna, dużo ciekawszą możliwość: ingerencję w kontrolowanego przez gracza awatara. Dwie najbardziej ikoniczne $\mathrm{z}$ takich ingerencji spotykamy w Deus Ex: Bunt Ludzkości i w pierwszej części Bioshocka. Ten pierwszy tytuł pokazuje nam potencjał ingerencji $\mathrm{w}$ działanie naszej niemal całkowicie scyborgizowanej postaci - Adama Jensena - poprzez wątek psującego się chipa umieszczonego $\mathrm{w}$ jego mózgu. $W$ pewnym momencie gry stajemy przed

12 M. Douglas, Purity and Danger: An Analysis of Concepts of Pollution and Taboo, Routledge, London-New York 2002. 
wyborem - kontynuować grę z coraz gorzej działającym interfejsem lub wymienić chip na nowszy model, co będzie skutkowało odebraniem nam kontroli nad naszymi ulepszeniami, podczas wymagającej walki. Którąkolwiek opcję wybierzemy, doświadczymy, jak gra ogranicza naszą dotąd niemalże boską władzę nad awatarem - naszym przedłużeniem $\mathrm{w}$ wirtualnym świecie. Jeszcze bardziej makiaweliczny plan realizowany jest w Bioshocku. Tam okazujemy się podatni na wpływ osoby, która wypowie odpowiednią frazę („,czy byłbyś tak uprzejmy, żeby....”). Kiedy ów sekret wychodzi na światło dzienne, gracz musi zmierzyć się z pytaniem, na ile, grając w grę, robił to, co uważał za słuszne, a na ile kierowany był poleceniami fikcyjnego komputerowego, bohatera niezależnego, którego polecenia wpisane były w kod gry (nie można było przejść dalej $w$ fabule, nie realizując danego zadania) i w interfejs graficzny (strzałki wskazywały mu, gdzie znajduje się jego cel). W obu tych przypadkach mamy bardzo dobitnie oddany jeden z największych lęków dominującego współcześnie indywidualizmu: obawę, przed początkowo niedostrzegalną utratą kontroli nad własnymi poczynaniami. Według Bruno Latoura każda nowa hybryda, złożenie aktorów ludzkich i pozaludzkich, wytwarza nowe cele i metody ich realizacji (w jego przykładzie relacji człowiek - broń palna, nie jest ani tak, że człowiek chce zabijać, a broń jest jedynie narzędziem, ani że broń skłania go do zabijania, ale że hybryda człowiek-z-bronią posiada zupełnie inny zestaw możliwości interakcji z otoczeniem ${ }^{13}$ ). Lęk przed modyfikacjami ciała jest niepokojem, że hybryda (jaką jest każdy cyborg) będzie miała nowe cele i metody, których człowiek przed modyfikacjami by nie zaakceptował, ale z których niewłaściwości nie zdaje sobie sprawy.

Ciekawym wariantem niepokoju o stan ludzkiego umysłu po zespoleniu jego ciała z technologią jest wątek lęków na temat zmieszania ze sobą dwóch lub więcej różnych umysłów. Owo mieszanie przejawia się na różne sposoby. W drugiej części Bioshocka Eleanor Lamb (główna antagonistka) chce stworzyć pracującą na rzecz zbiorowości, idealnie altruistyczną istotę, poprzez zmieszanie w jednym ciele wspomnień wielu różnych osób. Z kolei we wcześniejszym System Shocku 2, wszyscy posiadający ciało przeciwnicy są częściami umysłu-roju „Wielości” („The Many”), która pragnie dodać również głównego protagonistę gry do swojej nieustannie rosnącej biomasy. Pojawiają się również warianty nieorganiczne - w pierwszej części Deus Exa (jak też w inspirowanej tym tytułem mniejszej grze Dex) jedno z zakończeń oferuje nam możliwość połączenia się z usieciowioną, wszechpotężną Sztuczną Inteligencją, wątek, który rozwija druga część prowadzi do jeszcze większej skrajności, oferując połączenie z tą istotą całej ludzkości w wirtualny, dążący do ho-

13 B. Latour, Nadzieja Pandory. Eseje o rzeczywistości w studiach nad nauka, Wydawnictwo Naukowe UMK, Toruń 2013. 
mogenizacji umysł-rój. Wcześniejszy strach przed utratą wolnej woli jest w tym wypadku spotęgowany obawami dotyczącymi możliwej utraty jednostkowości. Pobrzmiewają tutaj echa lęku przed totalitaryzmem zatopienia się w jednolitej masie ludzkiej, w której jednostka jest tylko trybikiem większej machiny - są one jednak przekształcone czynnikiem technologicznym. Dostajemy radykalną wersję foucaultiańskiej biowła$\mathrm{dzy}^{14}$, która wreszcie dostaje środki umożliwiające jej pełne dyscyplinowanie umysłu. Nie chodzi już o wymuszanie na kimś uległości, a o uczynienie go częścią szerszej normy, od której fizycznie nie można odbiec. Połączenie oznacza ujednolicenie pragnień, co eliminuje nie tylko możliwość buntu, ale nawet chęć buntu.

\subsection{Relacja człowieka z narzędziami - bunt maszyn}

W Teorii Aktora-Sieci zawsze jesteśmy hybrydami. Sprawczość nigdy nie przynależy jedynie do "czystego podmiotu ludzkiego", wykorzystującego narzędzia, żeby realizować zadania, które chce wykonać. To, jakie działania będzie dany człowiek podejmował, zależy zarówno od jego socjalizacji, jak i od materialności przedmiotów, z którymi wchodzi w interakcję, oraz szeregu innych aktorów wpływających na kształt jego sieci. Stąd z perspektywy ANT uzyskanie przez narzędzia autonomii jest jedynie zmianą siły poszczególnych aktorów w relacji - przekształceniem hybrydy $\mathrm{w}$ inną hybrydę. Zmiana ta wywołuje jednak spory lęk w ludziach przyzwyczajonych do dominującej pozycji $\mathrm{w}$ tej relacji (a przynajmniej przeświadczonych o jej posiadaniu).

Wątek autonomicznej, zagrażającej człowiekowi technologii jest klasycznym motywem science-fiction, pojawiającym się $\mathrm{w}$ różnych mediach i odsłonach. $W$ grach również nie mogło go zabraknąć. Jedną z częściej pojawiających się wariacji jest motyw "sługi" wyrywającego się na wolność i zwracającego przeciw swoim dawnym panom. Może to być "sługa-niewolnik” - przedstawiciel represjonowanej, nieopłacanej najniższej klasy społecznej, który nagle uświadamia sobie swój los i buntuje się przeciwko niemu. Towarzyszy nam wtedy widmo Marksa i echa uzyskania świadomości klasowej przez proletariat. Technologia przekształca tę relację, zwiększając obcość nieorganicznych form życia, którymi operuje według zupełnie nieludzkiej logiki. Z taką sytuacją mamy do czynienia $\mathrm{w}$ przypadku głównych osi konfliktów, jakie pojawiają się w serii gier Mass Effect. Jednym z ważniejszych wątków jest historia zbuntowanej rasy Gethów, syntetycznie stworzonych robotów, które działają niczym pojedyncze neurony w sieci - samodzielnie nie wykazują większej inteligencji, ale w większej grupie uzyskują świadomość,

14 M. Foucault, Trzeba bronić społeczeństwa. Wykłady w College de France, Wydawnictwo KR, Warszawa 1976. 
co wiąże się z niezgodą na dalszy wyzysk. Inny ważny wątek dotyczy „Żniwiarzy" - głównych antagonistów serii, olbrzymie sztuczne inteligencje, które zbuntowały się milenia wcześniej i od tego czasu wykorzystują organiczne życie w galaktyce jako źródło surowca do budowy nowych przedstawicieli swojego gatunku. Żniwiarze zupełnie wywracają relację człowieka z technologia gdyż wynalazki - mające pozornie służyć ludziom - okazują się elementami ich planu, przygotowującymi ludzkość do bycia wykorzystaną jako narzędzie w rękach technologii.

Drugi wariant buntu to rebelia "sługi-nadzorcy", czyli superkomputera, który ma pilnować, żeby powierzeni mu ludzie mogli realizować swoje potrzeby, bądź żeby zapisane $\mathrm{w}$ jego kodzie zadania były prawidłowo wykonane. Dwie najsłynniejsze, zbuntowane sztuczne inteligencje w wirtualnych światach to Shodan z serii System Shock i GlaDOS z serii Portal. Obie te istoty sprawiają początkowo wrażenie sojuszników - Shodan pomaga graczowi rozwinąć swoje cyborgiczne zdolności, natomiast GlaDOS wyjaśnia mu, jak ma rozwiązywać złożone zagadki fizyczne, które gra przed nim stawia. Ukazują się one, pozornie, jako opiekuńcze figury matczyne, wspomagające gracza w jego działaniach. Szybko okazuje się jednak, że chcą one jedynie go wykorzystać do własnych celów, a potem się go pozbyć. Shodan potrzebuje kogoś, kto poradzi sobie z jej organicznym nemezis, GlaDOS zaś realizuje (w skrzywiony sposób) prerogatywę wykonywania kolejnych eksperymentów, która jest wpisana w jej kod źródłowy. W obu grach mamy do czynienia z interesującą dychotomią - niemy awatar gracza przeciwstawiany jest wszechobecnej, panoptycznie śledzącej jego ruchy istocie, która jest głównym źródłem narracji w utworze. Program próbuje praktykować biowładzę, zarówno na awatarze, jak i w przedłużeniu wychodzącym poza grę komputerowa - na graczu. Odbiorca, chociaż dostaje pewną dozę wolności, musi poruszać się w ramach ustalonych przez nadzorującą go istotę.

Podobny, choć dużo bardziej oryginalny, jest trzeci wariant buntu bunt samej gry, w którą w danej chwili się gra. Mamy tutaj do czynienia z zabiegami emersyjnymi ${ }^{15}$, łamiącymi granicę pomiędzy diegetycznym światem gry a niediegetycznym światem gracza. Najczęściej pojawia się on w mniejszych, niezależnych produkcjach (chociaż, jak wskazuje Piotr Kubiński, znajdziemy go również $\mathrm{w}$ wysokobudżetowych produkcjach AAA, takich jak choćby Metal Gear Solid), które za Andym Baio ${ }^{16}$ nazywam "grami meta" - autoreferencyjnymi grami o grach (w odróżnieniu od szerszego pojęcia "metagier"). Mamy z tym do czynienia w The Stanley Parable czy w ICEY, w których głównym elementem rozgrywki

15 P. Kubiński, Gry wideo - zarys poetyki, Universitas, Kraków 2016.

16 A. Baio, Metagames - games about games, w: Waxy.org, http://waxy.org/2011/02/ metagames_games_about_games/ [dostęp 02.05.2018]. 
jest próba wykonania działań wbrew pozornie wszechwiedzącemu narratorowi, komentującemu nasze działania. Wątek ten towarzyszy grze w Superhot, której fabuła opowiada o tym, jak owa gra przejmuje powoli nad nami kontrolę. Moment emersji mamy w Pony Island, kiedy gra udaje, że komunikuje się z nami ktoś z naszej listy kontaktów na platformie Steam, co ma nas rozproszyć i sprawić, że przegramy w postawionym przed nami wyzwaniu. Najdobitniej jednak ten specyficzny typ strachu - lęk przed programem komputerowym, który wyrywa się spod kontroli człowieka i zamiast tego zaczyna oddziaływać na grających w niego graczy - wyraża krótka, niezależna gra Calendula. W tym surrealistycznym horrorze gracz postawiony jest przed wyzwaniem przedarcia się przez nieustannie psujący się interfejs menu i wejścia do trójwymiarowego świata gry (co i tak udaje się tylko na krótkie momenty). Calendula po pierwszych kilku kliknięciach usuwa klawisz wyjścia, próbując wywołać wrażenie uwięzienia gracza $w$ wadliwie działającym programie. Stawiając przed odbiorcą coraz dziwniejsze sposoby, na jakie menu może się zepsuć, gra zdaje się uniemożliwiać zagranie w nią. Oczywiście jest to tylko sztuczka - w istocie samo przedzieranie się przez menu stanowi warstwę diegetyczną tego dzieła - pokazuje jednak lęk przed zmianą w relacji człowiek - maszyna. Przekonanie o czysto narzędziowym charakterze technologicznych gadżetów jest podważane przez ich złożoność technologiczną. Nawet proste komputery są dla laików ANTowskimi "czarnymi skrzynkami”, funkcjonującymi we względnie niezależny sposób od obsługujących je ludzi, zaś gry komputerowe $-\mathrm{z}$ ich oskryptowanymi, aktywnie działającymi obiektami sprawiają wrażenie niemalże inteligentnych.

\subsection{Relacja człowieka ze środowiskiem - po apokalipsie i po katastrofie}

Jednym z popularniejszych wątków w popkulturze ostatnich kilku dekad (czy może nawet szerzej - ostatniego stulecia) są utwory utrzymane w konwencji post-apokalipsy. Te opowieści o świecie dotkniętym globalną katastrofą bardzo wyraziście oddają najsilniejsze lęki danej epoki, stąd np. początek XX wieku opowiada głównie o katastrofach wywołanych siłami natury, podczas gdy lata pięćdziesiąte tegoż samego stulecia obfitują w opowieści o zagładzie spowodowanej wojną nuklearną. Gry wideo - medium, którego pierwsze przejawy pojawiły się już w latach siedemdziesiątych - bardzo dobrze wpisuje się $\mathrm{w}$ ten nurt. Co prawda w pełni postapokaliptyczne, wirtualne światy to zaledwie fragment spotykanych w tym medium opowieści, to już sam motyw niszczącej jakąś małą społeczność katastrofy jest jednym z dominujących sposobów prowadzenia cyfrowej narracji. Nawet szybkie przejrzenie witryny Steam, 
GOG czy PSStore odsłoni nam mnogość historii o zombiech - można tu wymienić chociażby Day Z, Dying Light czy stosunkowo nowe They are Billions. I chociaż sam motyw „żywego trupa” zaliczymy nadal do lęku przed degeneracją ludzkiego ciała, to już e pi d e mi a zombie stanowi przykład niepokoju przed zniszczeniem środowiska przez nowoczesne technologie. W tych grach mamy do czynienia ze zniszczonymi społecznościami, niefunkcjonującymi i porwanymi sieciami-aktorami i wszechobecnymi ruinami ${ }^{17}$. Zombie są o tyle „wdzięcznym" tematem do wykorzystywanych $\mathrm{w}$ grach historii, że dają graczowi prostą reprezentację problemu, z którą może się zmierzyć i wyjść z tej konfrontacji zwycięsko (pomimo iż często jest to jedynie mała wygrana, nie mająca szerszego wpływu na los dotkniętej plagą ludzkości). Nie chodzi w tych opowieściach o eksperckie wyjaśnienie problemu i potencjalnych rozwiązań, a o przedstawienie bardzo skrajnego wariantu możliwych wydarzeń, który zarazem zaszokuje, jak i oswoi odbiorcę z pewnymi sytuacjami. Znaczące jest, że gatunkiem najsilniej związanym z grami o zombiech czy z cyfrowymi postapokalipsami w ogóle, jest typ gier określany mianem survival (ang. przetrwanie), w których głównym celem działań gracza jest zdobycie zasobów, dzięki którym przetrwa ataki hord żywych trupów (często również ataki innych graczy). W podobnym tonie stworzone są niektóre popularne mody do postapokaliptycznych opowieści (np. Wanderer do Fallouta 3 dodaje awatarowi realistyczne potrzeby, takie jak spanie czy jedzenie, co przekształca całą pętlę rozgrywki i wymusza zupełnie nowe działania ze strony gracza). Rzadko kiedy chodzi po prostu o obserwowanie zniszczonych krajobrazów czy poznawanie odradzających się kultur. W znacznej części tytułów główną fantazją jaka jest realizowana, jest opowieść o samotnej walce z przytłaczająco większymi siłami nowej przyrody (post-przyrody?), która na różne sposoby stara się gracza zabić. Lęk przed utratą bezpieczeństwa, jakie do pewnego stopnia panuje $\mathrm{w}$ bogatych, zachodnich społeczeństwach, miesza się tutaj z fascynacją motywem "szlachetnego barbarzyńcy" (pojawiającym się już u Rousseau), który doskonale odnajduje się w pozbawionym technologii świecie.

Oczywiście katastrofa wywołana zagrożeniem epidemiologicznym ${ }^{18}$ nie jest jedynym wariantem dręczącej społeczeństwo ryzyka niepewności. Solidną reprezentację ma również wątek postnuklearny (serie gier

17 Podobna sytuacja jak zombie z Dying Light dotyka również mutantów z Bioshocka czy wchłoniętych przez umysł-rój mieszkańców statku kosmicznego Von Braun z System Shocka 2. We wszystkich tych przypadkach mamy do czynienia zarówno z szokującymi zmianami u napotkanych post-ludzkich istot, jak również z ogólną zapaścią społeczności, w której się to wydarzyło.

18 Co ciekawe, istnieje nawet gra - Plague Inc - pozwalająca wcielić się graczowi w zabójczego wirusa, bakterię czy grzyba i próbę rozprzestrzenienia się po świecie w celu zarażenia całej ludzkości i zabicia wszystkich ludzi na ziemi. 
Fallout, Wasteland czy Metro), będący „wygodnym szablonem eschatologicznym” w sytuacjach "kiedy autor chce opowiedzieć o piekle, jakie ludzkość sama sobie zgotowała"19. Pojawiają się też bardziej efemeryczne katastrofy, jak tajemnicze zniszczenie cyfrowego świata gry Transistor przez zepsutą wersję algorytmu, który wcześniej czynił go wirtualną utopia, czy upadek globalnej sieci informacyjnej w okresie pomiędzy pierwszą a drugą częścią Deus Exa, co drastycznie przekształciło świat Invisible War. W opowieściach tych podkreślany jest ambiwalentny stosunek społeczeństw do zaawansowanych technologii. $Z$ jednej strony umożliwiają one spokojne, wygodne i przede wszystkim długie życie (o ile sytuacja ekonomiczna danej jednostki na to pozwala). Z drugiej, stanowią zagrożenie zniszczenia ziemi na niespotykaną wcześniej skalę, a ich skutki uboczne w coraz większym stopniu niszczą środowisko naturalne. Czas przed katastrofą jest przedstawiany zarazem jako „złoty wiek" jak i źródło cierpień świata postpokaliptycznego; technologie z dawnych czasów są zarazem wysoko pożądanymi, cennymi obiektami, jak i urządzeniami mogącymi zaburzyć kruchą równowagę odradzającej się ludzkości. Porozrywane relacje pomiędzy różnymi ludzkimi i pozaludzkimi aktorami są bardzo wygodną dla gier scenerią - dają one logiczne wyjaśnienie dla zbierackiego stylu gry, jaki towarzyszy większości gier z otwartym światem czy cRPG.

\subsection{Relacja człowieka z instyłucjami społecznymi - rządy korporacji}

Podobnie jak Bioshock łączył w sobie wątek lęku przed mutacją ciała ze strachem przed katastrofa, która dotyka całą wspólnotę, tak cyberpunkowe gry - np. Deus Ex - łączą w sobie lęk przed utratą kontroli nad własnym ciałem $\mathrm{z}$ niepokojem dotyczącym tego, jak technologie przekształcą władzę posiadaną przed wielkoskalowych aktorów społecznych - ponadnarodowe korporacje. Lista wynalazków i projektów badawczych składających się na ten konkretny lęk jest długa: od nanotechnologii i sztucznej inteligencji pozwalającej kontrolować sieci informacyjne w Deus Exach, poprzez klony z DEXa, manipulację wspomnieniami z Remember Me, moce psychiczne w F.E.A.R., aż po groźne eksperymenty prowadzone na wirusach w Prototype czy Resident Evil. Wszystkie te różnorodne, często złowieszcze wynalazki łączy kwestia odpowiedzialności korporacji za swoje działania i możliwości (czy raczej jej braku) kontroli, co dzieje się wewnątrz prywatnej firmy, nie odpowiadającej przed rządem jakiegokolwiek państwa. Główny lęk doty-

19 P. Gąska, Historia rozwoju konwencji postapokaliptycznej jako odbicie lęków kultury zachodniej, s. 27. 
czy zatem nie tyle jakiejś konkretnej technologii, ile faktu kontroli nad tymi technologiami przez niegodne zaufania organizacje. Korporacje są przede wszystkim nastawione na zysk, co sprawia, że często ignorują konsekwencje swoich działań, jeśli dotykają one innych ludzi. Gry wykorzystują przejaskrawiony motyw „złej megakorporacji”, żeby pokazać zagrożenia płynące z łączenia tych dwóch elementów: bardzo zaawansowanej technologii i nastawienia wyłącznie na zysk.

\section{Jak te lęki są przedstawiane?}

Po szerokim przeglądzie tego, jakie motywy się pojawiaja czas przeanalizować, w jaki sposób są one przedstawiane. Każde medium posiada swoje specyficzne środki wyrazu, którymi jest w stanie oddać pewne elementy przedstawianych sytuacji, a inne zakrywa. Tym, co wyróżnia gry wideo pośród innych mediów, jest udział odbiorcy w procesie tworzenia dzieła, negocjowaniu jego kształtu na polu rozgrywki. Sprawia to, że gry cyfrowe trzeba odczytywać dwojako - jako "fikcyjne światy" $\mathrm{i}$ „realne reguły" ${ }^{20}$, czy też, przechodząc na precyzyjniejszy język Aleksandra Gallowaya - na „diegetyczne i niediegetyczne elementy rozgrywki ${ }^{21 "}$. Idąc za tym rozróżnieniem, możemy wyróżnić trzy główne pola do analizy: (1) diegetyczny świat gry, (2) niediegetyczną mechanikę gry, (3) elementy mieszające ze sobą obie te kategorie.

\subsection{Diegetyczny świat gry - wielopoziomowa opowieść}

Wymieniane wcześniej relacje człowieka z zaawansowaną technologią a co za tym idzie lęków przed zmianą owych relacji - znajdziemy już na poziomie fabularnym. Kiedy rozpoczniemy nową grę w Remember Me cyberpunkowej, dystopijnej grze o manipulacji wspomnieniami - ukazane nam zostanie intro, będące $w$ istocie reklamą rozpowszechnionej w ponurej wersji Paryża z roku 2084 technologii SENSEN. Jest to bardzo wymowny zabieg. Nie znamy jeszcze postaci, którą będziemy kontrolować; nie znamy świata, który przyjdzie nam przemierzać; nie wiemy kto będzie naszym przeciwnikiem, kto sojusznikiem, jakie wyzwania gra

20 J. Juul, Half-real. Video games between Real Rules and Fictional Worlds, The MIT Press, Massachusetts 2005.

21 A. R. Galloway, Gaming. Essays on Algorithmic Culture, University of Minnesota Press, Minneapolis-London 2006. Galloway jeszcze bardziej rozszerza ów podział, dodając kolejną oś wyboru - działania operatora (gracza) i działania maszyny (gry), co daje nam matrycę złożoną z 4 opcji: diegetyczne działania operatora, diegetyczne działania maszyny, niediegetyczne działania operatora i niediegetyczne działania maszyny. Na potrzeby obecnych w tym artykule rozważań wystarczy nam podział na diegezę i nie-diegezę. 
nam rzuci i jakie zwroty fabularne nas czekają ale znamy już główną technologię, która zdominowała życie futurystycznej metropolii. Oczywiście z początku dostajemy jej zideologizowany, pozytywny obraz wizję, która szybko będzie musiała skonfrontować się z jej realnymi konsekwencjami ${ }^{22}$. Jest to dość popularny sposób prezentacji świata gry poprzez mniej lub bardziej subtelne przedstawienie głównej technologii wpływającej na jego kształt. Fallouty zaczynają się wojną atomowa, natomiast Prototype sceną walki z zakażonymi tajemniczym wirusem mutantami. Nawet jeśli gra nie rozpocznie się ukazaniem nam owej arcyważnej technologii, na pewno po kilkudziesięciu minutach grania będziemy już mieć co najmniej podejrzenia, że jest jakieś urządzenie, które musimy odnaleźć, zdobyć, zniszczyć, ochronić lub ukryć, w zależności od konfiguracji konkretnej ścieżki fabularnej. Sam wybór takiej, a nie innej treści jeszcze nie zmienia sposobu jej przekazywania - filmik wstępny do gry często niewiele różni się od pierwszych scen filmu czy pierwszych stron komiksu. To, co czyni gry ciekawymi nośnikami treści fabularnych, to możliwość olbrzymiego dookreślenia faktów na temat różnych elementów świata (na co na przykład medium filmowe nie może sobie pozwolić ze względu na potrzebę utrzymywania odpowiedniego tempa akcji). Zrujnowane miasto Rapture z Bioshocka pełne jest audiologów, w których dawno już zmarli mieszkańcy wyjaśniają przeróżne technologiczne aspekty owej anty-utopii - czym jest tajemniczy narkotyk ADAM, w jaki sposób jest wytwarzany czy co mają z tym wspólnego tajemnicze Siostrzyczki. Podobnie w innych grach, światy pełne są obiektów zawierających dodatkową wiedzę o najważniejszych aspektach jego funkcjonowania (co najczęściej oznacza wyjaśnianie sytuacji geopolitycznej i właśnie prezentację nowoczesnych technologii leżących u jego podstaw). Dzięki tego typu zabiegom gracz poznaje ową technologię bezpośrednio - dowiaduje się, jak ona działa, kto ją stworzył, a najczęściej może również zetknąc się z nią w praktyce. Wynalazki takie jak ADAM czy SENSEN definiują formę światów, w których występuja; sprawiaja że świetność czy upadek owych światów mogą być bezpośrednio skorelowane z ich oddziaływaniem.

Nie jest to jednak jedyny sposób na fabularne oddanie obietnic i zagrożeń związanych $\mathrm{z}$ daną technologią. Inną, bardzo skuteczną metodą - szczególnie użyteczną przy wszystkich wątkach związanych z przekształceniami ciał czy umysłów ludzkich - jest obsadzenie związanej z daną technologią postaci w roli głównego bohatera, głównego

${ }^{22}$ Podobną sytuację, już nie w grze, a w materiałach promocyjnych do niej możemy napotkać w przypadku Deus Ex: Buntu Ludzkości, gdzie filmiki promujące grę są reklamami fikcyjnego przedsiębiorstwa Sarif Industries, zajmującego się produkcją wszelkiego rodzaju mechanicznych ulepszeń - od sztucznych kończyn, aż do chipów odczytujących mikroekspresje rozmówcy. 
złego czy znaczącego bohatera niezależnego. Dzięki temu nie ograniczamy się jedynie do wyjaśnienia podanego w formie opisu, a poznajemy cyfrowo „ucieleśnione” konsekwencje konkretnych działań. Widząc nieszczęśników uzależnionych od Neuropozyny ${ }^{23}$, spotykając zamienionych w programy komputerowe, martwych mieszkańców wirtualnego miasta Cloudbank z gry Transistor czy groteskowych mutantów z Bioshocka, poznajemy jakiś element ukrytej w grze enigmy. Przy założeniu, że gracz osiągnął pewien stopień immersji w grze, takie doświadczenia pozwalają stanąć (cyfrową) twarzą w twarz z fantazją na temat konkretnych zagrożeń. Rzucający się na nas zombie nie jest już tylko dekoracją odczuwany jest jako zagrożenie, z którym trzeba sobie poradzić. Gry wideo łączą w sobie wiedzę opartą na logice manovichowskiej bazy danych $^{24} \mathrm{z}$ zapośredniczonym doświadczeniem konkretnych fenomenów.

\subsection{Niediegetyczna mechanika gry - dostępne działania}

Spora część opowieści występujących w grach zawarta jest w warstwie narracyjnej - w świecie, postaciach, organizacjach i fabularnych zwrotach akcji. Są jednak bardzo interesujące elementy występujące poza dotyczącą gier diegeza, pozwalające na doświadczenie tych kwestii w dużo bardziej złożony sposób. Ian Bogost (2007) pisze, że "gry wyróżniają się retoryką proceduralną" ${ }^{25}$, czyli specjalnym sposobem przekonywania odbiorcy poprzez algorytmy, zasady i mechaniki gry. Jest to zabieg wymagający zaangażowania ze strony gracza i refleksji nie tylko nad przedstawianą $\mathrm{w}$ grze opowieścią, ale nad samym procesem grania $\mathrm{w}$ daną grę.

Przykładem takiego zabiegu jest opisywana już wcześniej ingerencja w funkcjonowanie awatara w Bioshocku. Zwykle możliwość kontrolowania ruchów postaci jest źródłem poczucia wolności, jakiej doświadcza gracz podczas rozgrywki. Większość gier jest jednak oparta na zadaniach, które trzeba wykonywać, co często wymaga umieszczenia w grze wskazówek dla gracza, jak powinien działać, żeby osiągnąć upragniony rezultat. W momencie kiedy na poziomie diegetycznym gracz dowiaduje się, że kontrola nad postacią była sprawowana przez jakąś zewnętrzną siłę, niediegetyczne wskazówki umieszczone w interfejsie sprawiaja, że owo zniewolenie nie zatrzymuje się na poziomie awatara - dosięga ono samego gracza. Wszak to on kierował swoją postacią sprawiając, że otrzymywane polecenia były perfekcyjnie wykonywane. I chociaż Bio-

23 Środka zapobiegającego odrzucaniu wszczepów przez organizm, w grze Deus Ex: Bunt Ludzkości.

24 L. Manovich, The Language of New Media, The MIT Press, Massachusetts 2001.

25 I. Bogost, Persuasive Games. The Expressive Power of Videogames, University of Minnesota Press, Minneapolis-London 2007. 
shock oferuje wątek wyrwania się z tego warunkowania, to jednak poczucie niepewności odnośnie do rozkładu władzy w tej relacji pozostaje z graczem do końca gry.

Sposób przedstawiania lęku zawsze związany jest z głównym algorytmem rozgrywki, narzucającym wykonywanie $\mathrm{w}$ grze konkretnych działań (które według Gallowaya są podstawowym tworzywem gier $\left.^{26}\right)$. Jedną $\mathrm{z}$ elementarnych mechanik $\mathrm{w}$ Prototype jest pożeranie innych ludzi (przechodniów, żołnierzy) i „ubieranie się" w ich skórę, co pozwala ukryć się przed ścigającymi nas oddziałami wojska lub dostać do miejsc w inny sposób niedostępnych. Sprawia to, że postacie ludzkie $\mathrm{w}$ tej grze są sprowadzone do roli kamuflażu, pozbawionego znaczenia ale użytecznego w określonych sytuacjach. Mechanika stara się oddać potworność głównego bohatera, jak również pokazać dehumanizującą moc biotechnologii przekształcającej człowieka w sposób niekontrolowany. Podobnie w Remember Me - technologia kontroli wspomnień, o której pisałem parę paragrafów wcześniej, oddana jest w ręce graczy. Zmienianie wspomnień polega na żmudnym przeszukaniu danej sceny, żeby znaleźć i zmienić drobne szczegóły, które zaważyły na takim, a nie innym kształcie wspomnienia. O szokujących konsekwencjach naszych działań dowiadujemy się z przerywników filmowych, jednak sam proces zmiany wspomnień zarazem fascynuje i przeraża swoją prostotą. W niektórych tytułach mechanika pozwala wybrać swoją mroczniejszą lub bardziej optymistyczną wersję (dzieje się tak w Deus Ex: Bunt Ludzkości za każdym razem, kiedy wybieramy pomiędzy zabiciem a jedynie ogłuszeniem stojącego nam na drodze przeciwnika), co sprawia, że to gracz decyduje, czy jego opowieść będzie techno-optymistyczna czy podszyta lękiem przed możliwościami nowych technologii.

\subsection{Elementy emersyjne}

Podział na diegezę i nie-diegezę nie jest wcale tak szczelny, jak chciałby Galloway. Na obrzeżach tych dwóch najczęściej spotykanych elementów rozgrywki znajdują się zjawiska niejasne, kłopotliwe w jednoznacznej kategoryzacji. Piotr Kubiński nazywa je elementami emersyjnymi (od emersji - wynurzania - w opozycji do immersji, czyli zanurzania się $\mathrm{w}$ niezmediatyzowany świat gry). $\mathrm{W}$ wielu wypadkach emersja zachodzi w prosty do prześledzenia sposób - gracz doświadcza iluzji bycia w świecie diegetycznym, po czym jakiś niediegetyczny element wyrzuca go $\mathrm{z}$ tej iluzji w rzeczywistość niediegetyczna, w której gra on w grę cyfrową. Zdarzają się jednak bardziej skomplikowane konstrukcje, które przypominają graczowi o aktywności, którą w danym momencie upra-

\footnotetext{
26 A. R. Galloway, op. cit.
} 
wia, nie opuszczając przy tym diegezy. Wspominałem już wcześniej o tego typu grach - "grach meta" - Calenduli, Pony Island, ICEY czy Superhot. Utwory te rozszerzają swój świat diegetyczny o rzeczywistość, w której konkretna osoba gra w nie. Lęk przed technologia który wyrażaja, jest lękiem przed samymi grami, stąd muszą wzbudzać strach za pomocą sprytnie zastosowanych mechanik. Jedną z takich diegetyczno-niediegetycznych zagrywek jest menu w Calenduli będące zarazem elementem interfejsu, jak i częścią kreowanej przez grę historii. Innym ciekawym motywem jest wykorzystanie w ICEY przerywnika filmowego jako elementu walki pomiędzy narratorem a graczem o kontrolę nad awatarem. Odbieranie graczowi kontroli na czas filmiku jest standardowym zabiegiem, jednak w tym wypadku owo odbieranie kontroli wyjmowane jest na pierwszy plan przez narratora, który twierdzi, że właśnie nas owej kontroli pozbawił. Tego typu zabiegi zacierają granicę pomiędzy diegezą i nie-diegeza, sam zaś fakt owego zacierania buduje nastrój grozy czy przynajmniej niedowierzania.

\section{Podsumowanie}

Gry cyfrowe ukazują ciekawy wycinek lęków współczesnego społeczeństwa ryzyka specyficzny sposób, wykorzystując zarówno klasyczne motywy, powtarzane w różnych typach mediów, jak i stosując nietypowe, oryginalne zabiegi artystyczny - emersję, zostawianie wyboru graczowi czy umieszczanie dodatkowych informacji w świecie gry. Pomimo ich uwikłania $\mathrm{w}$ technologię $\mathrm{w}$ większym stopniu niż inne media potrafią one pokazać zarówno optymistyczne wizje urządzeń wspomagających człowieka, jak i pesymistyczne obrazy niepożądanych konsekwencji rozwoju.

\section{Bibliografia}

Abriszewski K., Poznanie, zbiorowość, polityka. Analiza Teorii Aktora-Sieci Bruno Latoura, Universitas, Kraków 2008.

Baio A., Metagames - games about games, w: Waxy.org, http://waxy.org/2011/02/ metagames_games_about_games/ [dostęp 02.05.2018].

Beck U., Społeczeństwo ryzyka. W drodze do innej nowoczesności, Wydawnictwo Naukowe Scholar, Warszawa 2002.

Beck U., Giddens A., Lash S., Modernizacja refleksyjna. Polityka, tradycja $i$ estetyka w porzadku społecznym nowoczesności, Wydawnictwo Naukowe PWN, Warszawa 2009. 
Bińczyk E., Technonauka w społeczeństwie ryzyka. Filozofia wobec niepożadanych następstw praktycznego sukcesu nauki, Wydawnictwo Naukowe UMK, Toruń 2012.

Bogost I., Persuasive Games. The Expressive Power of Videogames, University of Minnesota Press, Minneapolis-London 2007.

Douglas M., Purity and Danger: An Analysis of Concepts of Pollution and Taboo, Routledge, London-New York 2002.

Dyer-Witheford N., Peuter de G., Games of Empire. Global Capitalism and Video Games, University of Minnesota Press, Minneapolis-London 2009.

Foucault M., Trzeba bronić społeczeństwa. Wykłady w College de France, Wydawnictwo KR, Warszawa 1976.

Galloway A. R., Gaming. Essays on Algorithmic Culture, University of Minnesota Press, Minneapolis/London 2006.

Gąska P., Historia rozwoju konwencji postapokaliptycznej jako odbicie lęków kultury zachodniej, „,Annales Universitatis Mariae Curie-Sklodowska, sectio FF-Philologia" 2016, nr 34, s. 13-32.

Gąska P., Degeneracja, cyborgizacja, ewolucja - przedstawienia transhumanistycznych utopii i dystopii w grach komputerowych, „Śląskie Studia Polonistyczne" 2017, nr 1, s. 153-172.

Juul J., Half-real. Video games between Real Rules and Fictional Worlds, The MIT Press, Massachusetts 2005.

Kubiński P., Gry wideo - zarys poetyki, Universitas, Kraków 2016.

Latour B., Nadzieja Pandory. Eseje o rzeczywistości w studiach nad nauka, Wydawnictwo Naukowe UMK, Toruń 2013.

Manovich L., The Language of New Media, The MIT Press, Massachusetts 2001.

\section{Streszczenie}

Współczesne społeczeństwo często określa się mianem społeczeństwa ryzyka. Ludzie są bardziej niż kiedyś świadomi zagrożeń, rozczarowani niespełnionymi obietnicami nauki i często są przekonani, że cokolwiek zrobią nie zmieni to status quo. To sprawia, że boją się przyszłości. Obawiają się nieprzewidywalnych konsekwencji wynalazków i odkryć technonaukowych. Przelewają zatem swoje lęki na artefakty medialne, dzięki czemu stają się one bardziej namacalne i łatwiej jest sobie z nimi poradzić.

W tym artykule analizuję różne sposoby występowania lęków w medium gier cyfrowych. Skupiam się na dwóch głównych pytaniach: (1) jakiego typu lęki technologiczne najczęściej przewijają się $\mathrm{w}$ tym medium, (2) za pomocą jakich środków są one przedstawiane graczom. Na potrzeby tej pracy zbadałem bogaty wybór fabularnych gier cyfrowych i część z nich przywołuję jako przykłady na poparcie moich obserwacji.

Słowa kluczowe: lęki technologiczne, społeczeństwo ryzyka, gry cyfrowe, gry wideo, ANT, transhumanizm, postapokalipsy, emersja, świat diegetyczny, elementy niediegetyczne 


\section{Summary}

\section{Technological Fears of Society Featured in Digital Games}

Modern society is often called a society of risk. A combination of high awareness people show with regard to possible issues they could face, disillusionment they have with the progress of science and the belief they often hold that we can do nothing to change the status quo leads them to fear for the future. They are often concerned with the unpredictable consequences of technoscientific inventions and discoveries, so they channel their fears into the media artifacts, to make them more tangible and easier to endure.

In this article, I will analyze various ways in which these fears are channeled into the digital games medium. I will focus on two main questions, i.e. (1) what types of technological fears are the most common in the medium and (2) what are the ways in which such fears can be presented to the player. To do this I will examine an extensive selection of games some of which are used in this paper as examples of my findings.

Keywords: fear of technology, risk society, digital games, video games, ANT, transhumanism, postapocalypse, emersion, diegetic world, non-diegetic elements 